\title{
A Multilevel Analysis of Classroom Goal Structures' Effects on Intrinsic Motivation and Peer Modeling: Teachers' Promoting Interaction as a Classroom Level Mediator
}

\author{
Kazuhiro Ohtani ${ }^{1}$, Ryo Okada ${ }^{2}$, Takamichi Ito ${ }^{3}$, Motoyuki Nakaya ${ }^{4}$ \\ ${ }^{1}$ Department of Human Sciences, University of Osaka, Osaka, Japan \\ ${ }^{2}$ Department of Education, University of Kagawa, Takamatsu, Japan \\ ${ }^{3}$ Department of Education, Kyoto University of Education, Kyoto, Japan \\ ${ }^{4}$ Departmentof Education and Human Development, Nagoya University, Nagoya, Japan \\ Email: yamato@hus.osaka-u.ac.jp
}

Received June $7^{\text {th }}$, 2013; revised July $8^{\text {th }}, 2013$; accepted July $17^{\text {th }}, 2013$

Copyright $(C) 2013$ Kazuhiro Ohtani et al. This is an open access article distributed under the Creative Commons Attribution License, which permits unrestricted use, distribution, and reproduction in any medium, provided the original work is properly cited.

\begin{abstract}
This study investigated how classroom goal structures (mastery and performance goal structures) related to intrinsic motivation and peer modeling focusing on teachers' promoting interaction as a classroom level mediator. Authors tested multilevel mediational models with a sample of 1212 Japanese elementary and junior high school students from 43 classrooms. Results provided support for classroom level mediational process in mastery goal structures. Specifically, mastery goal structures related to promoting interaction, and promoting interactions related to both intrinsic motivation and peer modeling. Limitations and future directions of the study were discussed.
\end{abstract}

Keywords: Classroom Goal Structures; Promoting Interactions; Intrinsic Motivation; Peer Modeling

\section{Introduction}

Students' learning is influenced by educational environment factors as well as individual factors. In particular, the classroom context, in which students spend a great deal of time every day, can be the most powerful predictor of achievement behaviors and academic outcomes. Previous motivation research has focused on classroom goal structures and has produced a number of findings (Kaplan, Middleton, Urdan, \& Midgley, 2002). This study examined the effects of classroom goal structures in terms of teachers promoting interaction among students.

\section{Achievement Goal Theory}

Recent motivational research has been led by achievement goal theory (e.g., Ames, 1992; Dweck \& Leggett, 1988; Maehr \& Zusho, 2009; Nicholls, 1984). Research on achievement goal theory has focused on the reasons why students try to succeed and has examined two types of achievement goals: mastery goal (also called learning goal or task goal) and performance goal (also called relative ability goal or ego goal). Mastery goals are defined in terms of focusing on developing one's competence, mastering a new skill, trying to accomplish a challenging task, and trying to understand learning materials. Success is evaluated in terms of self-improvement and internal norms. By contrast, performance goals are defined in terms of demonstrating competence and having high ability relative to others, striving to be better than others, and using social comparison standards to judge ability and performance. Success is derived from doing better than others and surpassing normative performance standards. In recent years, some researchers have added an approach-avoidance dimension and proposed a $2 \times 2$ framework of achievement goals (Elliot, 2005; Elliot \& McGregor, 2001). This conceptualization proposes four types of achievement goals: 1) mastery-approach goals, which focus on developing competence through task mastery; 2) masteryavoidance goals, which focus on the avoidance of task-based and intrapersonally based incompetence; 3) performance-approach goals, which focus on attaining competence relative to others; and 4) performance-avoidance goals, which focus on avoiding incompetence relative to others. However, few empirical studies have focused on mastery-avoidance goals.

Many researchers have examined individual-level achievement goals (i.e., personal goals). Personal goals refer to the specific goals that individuals strive to attain in achievement contexts. Personal achievement goals were found to be associated with various achievement behaviors and academic outcomes (Meece, Anderman, \& Anderman, 2006; Urdan \& Schoenfelder, 2006). Personal mastery goals were found to be associated with high academic self-efficacy, high levels of effort and persistence, use of learning strategies that enhance conceptual understanding, and intrinsic motivation. In contrast, pursuing performance-avoidance goals is usually associated with a negative pattern of motivational behaviors such as lesser persistence, avoidance of help-seeking, and self-handicapping. The effects of performance-approach goals are not sufficiently clear. Although pursuing performance-approach goals is associated with less persistence and use of surface-level learning strategies, students with higher levels of performance-approach goals tend to 
achieve higher academic performance (Harackiewicz, Barron, Pintrich, Elliot, \& Thrash, 2002).

\section{Classroom Goal Structures}

In addition to personal goals, achievement goals have been treated as a contextual-level factor of the classroom and school. Goal structures refer to messages in the learning environment that make certain goals salient (Ames, 1992). Classroomfocused research has examined how teachers may create different goal structures in their classrooms by using various instructional, evaluation, and grouping strategies (Kaplan et al., 2002). Ames and Archer (1988) designed and used self-report measures to assess the salience of mastery and performance goals in the classroom. In their study, students' perceptions of mastery goals were related to the use of learning strategies, preference challenge, and effort attribution. In contrast, perceptions of performance goals were associated with ability attribution and less favorable attitudes toward the class. Ames (1992) reported that mastery goals are made salient when value is placed on the process of learning through emphasis on meaningful learning, self-referenced standards, and opportunities for self-directed learning.

Researchers inspired by Ames' work have examined the effects of goal structures on achievement behaviors and academic outcomes. Mastery goal structures were found to be associated with academic self-efficacy (Midgley, Anderman, \& Hicks, 1995; Roeser, Midgley, \& Urdan, 1996), intrinsic motivation (Murayama \& Elliot, 2009), and self-regulated learning strategies (Wolters, 2004). In contrast, performance goal structures were related to academic self-consciousness (Roeser et al., 1996), avoidance of academic help-seeking (Ryan, Gheen, \& Midgley, 1998), and disruptive behavior (Kaplan, Gheen, \& Midgley, 2002). However, some researchers reported no negative effects of performance classroom goal structures (Midgley et al., 1995; Ryan \& Patrick, 2001). Classroom goal structures also have longitudinal effects on academic outcomes. Urdan and Midgley (2003) investigated the relationship between the change in goal structures from fifth to sixth grades and academic self-efficacy and academic achievement. Students who perceived an increase or no change in the mastery goal structures reported higher academic self-efficacy and attained higher academic achievement than students who perceived a decrease in the mastery goal structures.

Many researchers have focused on students' perceptions of classroom goal structures. On questionnaires, students reported their subjective perceptions of the emphasis in the classroom with respect to the purposes for engaging in academic tasks and the meanings associated with success and achievement. A questionnaire measuring students' perceptions of classroom goal structures has been developed and validated (Midgley, Maehr, Hruda, Anderman, Anderman, Gheen, Kaplan, Kumar, Middleton, Nelson, \& Urdan, 2000). Recently, classroom goal structures tend to be considered as group-level variables. A growing body of research distinguishes between classroomlevel variance and student-level variance and examines the effects of classroom goal structures by using multilevel analysis (Kaplan et al., 2002; Ryan et al., 1998; Turner, Midgley, Meyer, Gheen, Anderman, \& Kang, 2002). Because goal structure in any classroom is shared by students in the class, it is necessary to note the difference between variance of goal structures as a characteristic of the classroom and variance of goal structure as individual students' perceptions of the classroom.

Another line of researches has focused on the relationships between classroom goal structures and teachers' daily educational practices. Ames (1992) discussed how teachers' educational practices influence whether classrooms have characteristics of mastery goal structures or performance goal structures and proposed some instructional strategies. Some researchers with qualitative data revealed that teachers' discourse and instructional strategies had original characteristics in mastery or performance goal classrooms (e.g., Patrick, 2004; Patrick, Anderman, Ryan, Edelin, \& Midgley, 2001; Turner, Meyer, Midgley, \& Patrick, 2003; Turner et al., 2002). For example, Turner et al. (2002) observed sixth grade mathematics classrooms and stated that teachers conveyed mastery messages to their students through explicit admonitions not to feel inadequate or ashamed when they did not understand. Ames (1992) stated that teachers' instructional strategies led to students' mastery goals.

\section{Teachers' Promoting Interaction as a Mediator}

We focused on teachers promoting interaction as a teachers' educational practice that conveys mastery message to the students. Promoting interaction is one of the social climate of classroom that affects students' motivation and achievement, and refers to teachers' encouraging peer interaction among students, such as sharing ideas during whole-class lessons, working together in small-group activities, or informal helpseeking and help-giving during individual seatwork (Ryan \& Patrick, 2001). Ryan and Patrick (2001) reported that teachers varied in the extent to which they encouraged student interaction, and the encouragement led to students' academic achievement and motivation. Patrick, Ryan, and Kaplan (2007) examined the relationship between fifth-grade students' perceptions of promoting interaction (e.g., "My teacher often allows us to discuss our work with classmates") and their motivation. In the study, students who perceived that their teachers promoted interaction reported higher levels of academic self-efficacy and more task-related interaction. In addition, Patrick (2004) reviewed the relevant researchers and concluded that promoting task-related interaction is related to students' liking and interest of school and subject area (these are the components of intrinsic motivation).

In early literature of achievement goal theory, cooperative goal structures had been considered an important factor. Ames and Ames (1984) identified three types of classroom goal structures: cooperative, competitive, and individualistic goal structures. Ames and Ames (1984) defined cooperative goal structures as situations in which the probability of one student receiving a reward is enhanced by the presence of capable others. Cooperative goal structures involve interdependence among group members, where each member shares responsibility for the outcome or product. However, three types of goal structures evolved into distinctions between competitive environment (i.e., performance goal structures) and non-competitive environment (i.e., mastery goal structures), and cooperative goal structures and individualistic goal structures were integrated into mastery goal structures in the conceptualization process (Patrick, 2004). Thus, the mastery goal structures seem to include a nature of cooperative goal structures. That is, it is thought that teachers use cooperative educational strategies (i.e., promoting interaction) in mastery goal classrooms.

Classroom goal structures and teachers' educational instruc- 
tional practices seem to intertwine each other in the actual classrooms. In this study, we assumed the process in which classroom goal structures influence students' motivation and achievement related behaviors through teachers' instructional practices on the basis of Patrick, Kaplan, and Ryan's (2011) findings and discussion. Patrick et al. (2011) stated that "when students evaluate the extent to which their teacher promotes real understanding and personal improvement (i.e., emphasizes mastery goal structure), they draw from their perceptions of the teacher's messages about interpersonal relationships (e.g., support, respect, helping one another)" (p. 370). In addition, Patrick et al. (2011) found that mastery goal structures could account for the variance of social climate dimensions involving teachers promoting interaction. Although the mastery goal structures and teachers promoting interaction can be related reciprocally, we assumed the process in which the mastery message in the classroom are conveyed through teachers' educational practice and treated the promoting interaction as a mediator of the mastery goal structures.

\section{The Peer Modeling}

It is possible that teachers promoting interaction influences students' use of self-regulated learning. It is especially likely that students could develop learning strategies mediated by their peers (i.e., classmates or friends) in mastery goal classrooms. We focused on students' use of peer modeling as a self-regulated learning strategy. Peer modeling is the cognitive, affective, and behavioral change that derives from observing models (Schunk, 1998). In the classroom setting, children not only learn from direct interaction but also acquire knowledge and enhance their motivation by observing peers' learning behaviors. Therefore, peer modeling plays an important role in the learning process through which children acquire skills, behaviors, and beliefs.

Experimental research has revealed that peer modeling has a significant effect on children's academic achievement and motivation (Schunk, 1998; Schunk \& Hanson, 1985, 1989). Most of the findings about peer modeling have emerged from experimental studies in laboratories, and few studies have paid attention to the peer modeling that students use as learning strategies in their classrooms. However, peer modeling could play an important role in daily classroom learning activities (Brophy, 2004; Ryan, 2000). This study examined the effects of mastery goal structures mediated by teachers promoting interaction on students' use of peer modeling in the classroom.

It was possible that peer modeling was positively related to intrinsic motivation. Research of self-regulated learning has found that intrinsic motivation was associated with more use of various self-regulated learning strategies (Meece, Blumenfeld, \& Hoyle, 1988; Pintrich \& De Groot, 1990; Yamauchi \& Tanaka, 1998; Young, 2005). This means that intrinsically motivated students tend to use various self-regulated learning strategies in the learning situations. No research has examined the relationship between intrinsic motivation and peer modeling. Given that peer modeling is one of the self-regulated learning strategies, however, it was expected that intrinsic motivation was positively related to peer modeling in the classroom, although the relationship was not a main focus of this study.

\section{The Present Study}

We examined the effects of classroom goal structures on the students' motivation and peer modeling in terms of teachers promoting interaction. Based on the previous findings (Murayama \& Elliot, 2009; Patrick, 2004), this study focused on intrinsic motivation as students' motivation. We predicted that mastery goal structures would influence intrinsic motivation and peer modeling through teachers promoting interaction. As a school subject, we focus on mathematics classes. Turner and Meyer (2009) suggested that many children tend to experience difficulties in mathematical learning and consequently lose their confidence. Some researchers have examined the effects of goals structures in math classrooms (Kaplan et al., 2002; Ryan et al., 1998; Turner et al., 2002). Thus, we measured goal structures, teachers promoting interaction, intrinsic motivation, and peer modeling just in math classes.

In this research, classroom-level variances and student-level variances were partitioned, and we tested a multilevel mediation model. Because mastery goal structures and promoting interaction were classroom-level variables, we expected that the above mediation process would be confirmed, especially at the classroom level.

\section{Method}

\section{Participants and Procedure}

The sample consisted of Japanese public elementary (fifth and sixth graders) and junior high school students (seventh and eighth graders) in 43 classrooms (17 elementary, 26 junior high) in 10 schools from Kansai region. The final sample included a total of 1212 students (617 females, 591 males, 4 unspecified). Schools were recruited by contacting the board of education and then school administrators. Schools were selected by the board of education of the cities so that the diversity of students was maintained.

\section{Measures}

Classroom goal structures, teachers promoting interaction, peer modeling, and intrinsic motivation were all assessed with a questionnaire. All used a 6-point scale, ranging from 1 (not at all true) to 6 (very true). Each variable in this study was specific to the domain of mathematics.

Classroom goal structures. To assess classroom goal structures, ten items were created based on the works by Miki and Yamauchi (2005) and Midgley et al. (2000). These consisted of five items assessing mastery goal structure (sample item: "In math class, learning new things is important") and five items assessing performance goal structure (sample item: "In math class, getting a good grade is the important thing for students"). The reliability and validity of the original scale have been documented in prior studies (Midgley et al., 2000; Miki \& Yamauchi, 2005). To assess internal consistency of the scales, coefficient omega was calculated using a within-classroom covariance matrix. The coefficient omegas were .73 for mastery goal structure and .60 for performance goal structure.

Promoting interaction. To assess teachers promoting interaction, we developed four items based on the Ryan and Patrick's (2001) scale. Items were: (1) "In math class, our teacher says that cooperation in the group is important," (2) "In math class, our teacher says that talking to each other in a group is an important thing," (3) "In math class, our teacher emphasized that you need to help friends when you know the answers," and (4) "In math class, our teacher says that asking peers for help is 
important when one doesn't know the answer." Acceptable internal consistency was identified $(\omega=.77)$.

Intrinsic motivation. To assess students' intrinsic motivation for learning mathematics, we used Tanaka and Yamauchi's (2000) scale. Tanaka and Yamauchi's measure is a Japanese version of Elliot and Church's (1997) intrinsic motivation scale. For the purpose of this study, we selected three items that have shown high factor loadings on the basis of factor analysis in Tanaka and Yamauchi (2000). Items were (1) "I think this class is interesting," (2) "I enjoy this class very much," and (3) "I think this class is fun." The reliability and validity of the original scale have been documented in prior studies (Elliot \& Church, 1997; Tanaka \& Yamauchi, 2000). The scale showed high internal consistency $(\omega=.93)$ in this study.

Peer modeling. To assess peer modeling, four items were created based on Okada, Nakaya, Ito, and Ohtani's (2010) peermodeling scale and the conceptual description of peer modeling (Schunk, 1998). Items were (1) "I try to study like my friends with high motivation to learn," (2) "I try to follow friends' good performance," (3) "When I cannot solve the problem, I try to model my friends who can solve the problem," and (4) "When studying, I try to learn like my friends do." The scale was internally consistent $(\omega=.82)$.

\section{Results}

\section{Descriptive Statistics and Correlations of Study Variables}

Descriptive statistics and correlations are presented in Table 1. Correlations were calculated at the classroom level and student level. At the classroom level, mastery goal structure was positively related to promoting interaction $(\mathrm{r}=.77, p<.001)$, intrinsic motivation $(\mathrm{r}=.86, p<.001)$, and peer modeling $(\mathrm{r}$ $=.55, p<.05)$. Performance goal structure was not strongly related to other variables except for mastery goal structure $(\mathrm{r}=$ -.50 ). The same results were obtained at the student level. Mastery goal structure showed positive correlations with promoting interaction $(\mathrm{r}=.59, p<.001)$, intrinsic motivation $(\mathrm{r}=.28, p$ $<.001)$, and peer modeling $(\mathrm{r}=.45, p<.001)$. Correlation coefficients of performance goal structure were all below 21 .

\section{Analysis Plan}

This research tested how classroom goal structures related to intrinsic motivation and peer modeling using hierarchical linear modeling. As a first step, we conducted a preliminary analysis to check our variables' between-classroom variances and intraclass correlations. Next, we tested a multilevel mediation model (Zhang, Zyphur, \& Preacher, 2009) in which classroom goal structures indirectly influence outcome variables through promoting interaction. In the multilevel mediation model, variances of all variables were partitioned into classroom level and student level. Then, mediations were tested in both levels. Since our measurement of classroom level variables were students' perception, our multilevel mediation model equivalent to Zhan et al.'s (2009) 1-1-1 model. In 1-1-1 model, aggregated indicators of classroom goal structures and promoting interaction in each classroom were created for testing Level 2 mediational model. The 1-1-1 model is beneficial because it provides the information of both student and classroom level processes. The regression coefficients were reported in unstandardized coefficients.

A multiple imputation technique was used in all subsequent analyses. The method was beneficial compared to other techniques such as mean substitution or list-wise deletion. PASW 18.0 Missing Values was used to create five imputed data sets and integrated results were reported. All subsequent analyses were performed by HLM 7 with maximum likelihood estimation.

\section{Preliminary Analysis}

The analyses tested whether the variables were significantly varied among classrooms. The classroom goal structures significantly varied among classrooms: mastery goal structure, $\chi^{2}$ $(42)=206.48, p<.001$; performance goal structure, $\chi^{2}(42)=$ $265.91, p<.001$. Intraclass correlations were $12 \%$ and $16 \%$ respectively. We also checked reliability of classroom goal structures in case that the aggregation of student rating cause biased estimation in the classroom level (Bliese, 2000). The reliabilities were relatively high, .79 and .84 , respectively.

We also examined whether our mediator variable (i.e., promoting interaction) and outcome variables (intrinsic motivation and peer modeling) varied among classrooms and found the following significant between-class variances: for promoting interaction, $\chi^{2}(42)=319.5, p<.001$, for intrinsic motivation, $\chi^{2}$ $(42)=131.82, p<.001$, and for peer modeling, $\chi^{2}(42)=61.61$, $p<.05$. Intraclass correlations were $18 \%, 7 \%$, and $1 \%$, respectively. The reliability of promoting interaction was .86 .

\section{Multilevel Mediation Model}

Intrinsic motivation. For intrinsic motivation, we tested a multilevel mediation model (Zhang et al., 2009). As the first step of the meditational analysis, classroom goal structures were put in the model as both classroom-level and student-level predictors for the intercept of intrinsic motivation. Student-level variables were centered at group mean (Zhang et al., 2009). We

Table 1.

Descriptive statistics and Pearson product-moment correlations for the study variables.

\begin{tabular}{|c|c|c|c|c|c|c|c|c|c|c|c|c|}
\hline & & $N$ & $M$ & $S D$ & 1 & 2 & 3 & 4 & 5 & $N$ & $M$ & $S D$ \\
\hline 1 & Mastery goal structure & 1172 & 4.50 & 0.89 & - & $-.50^{* * *}$ & $.77^{* * *}$ & $.86^{* * *}$ & $.55^{*}$ & 43 & 4.48 & 0.35 \\
\hline 2 & Performance goal structure & 1146 & 3.23 & 0.97 & .05 & - & -.11 & $-.25^{\dagger}$ & .27 & 43 & 3.26 & 0.43 \\
\hline 3 & Promoting interaction & 1146 & 4.04 & 1.01 & $.59^{* * *}$ & $.15^{* * *}$ & - & $.87^{* * *}$ & $.81^{* * *}$ & 43 & 4.04 & 0.46 \\
\hline 4 & Intrinsic motivation & 1157 & 3.32 & 1.58 & $.28^{* * *}$ & $.12^{* * *}$ & $.20^{* * *}$ & - & $.72^{* *}$ & 43 & 3.33 & 0.50 \\
\hline 5 & Peer modeling & 1153 & 3.96 & 1.10 & $.45^{* * *}$ & $.21^{* * *}$ & $.46^{* * *}$ & $.36^{* * *}$ & - & 43 & 3.96 & 0.25 \\
\hline
\end{tabular}

Note: Descriptive statistics and correlation coefficients above diagonal represent classroom level, below diagonal represent student level. ${ }^{\dagger} p<.10,{ }^{* *} p<.01,{ }^{* * *} p<.001$. 
controlled grade (fifth grader $=0$, sixth grader $=1$ seventh grader $=2$, eighth grader $=3$ ) at classroom level, and gender (female $=0$, male $=1$ ) at student level because prior research has documented those variable are significant predictors of academic outcomes (Hyde \& Durik, 2005; Lepper, Corpus, \& Iyengar, 2005).

In the classroom level, the results suggested that mastery goal structure influenced intrinsic motivation $(\gamma=1.32, p$ $<.001)$. In contrast, performance goal structure did not reach significance, so we omitted performance goal structure from subsequent analyses at both levels (see Appendixes 1 and 2 for the final models and results). Next, we predicted that mastery goal structure was associated with promoting interaction and found significant positive relationships at classroom level $(\gamma=$ $1.24, p<.001)$. Finally, promoting interaction was put in the model as a mediator to predict the intercept of intrinsic motivation. Promoting interaction showed a significant relationship to intrinsic motivation $(\gamma=0.38, p<.05)$ at the classroom level. At this time, the coefficients of mastery goal structure reduced its value from $\gamma=1.32, p<.001$ to $\gamma=0.84, p<.01$. The results of Sobel's test determined that this mediation was significant ( $\mathrm{z}$ $=2.37, p<.05$ ).

In the student level of mediational analysis, student level mastery goal structure also a positive predictor of intrinsic motivation $(\gamma=0.50, p<.001)$, as well as promoting interaction $(\gamma$ $=0.65, p<.001)$. In contrast to findings at the classroom level, student-level promoting interaction did not show a significant relationship to intrinsic motivation $(\gamma=0.09$, n.s.). Figure 1 and Table A1 shows the final result.

Peer modeling. For peer modeling, we tested a multilevel mediation model with the same procedures as were used for intrinsic motivation. As the first step of the meditational analysis, classroom goal structures were put in the model as both classroom- and student-level predictors for the intercept of peer modeling. Grade and gender were controlled.

In the classroom level, the results suggested that mastery goal structure influenced peer modeling $(\gamma=0.56, p<.001)$. Finally, we tested the mediation and found a significant relationship between promoting interaction and peer modeling $(\gamma=$ $0.23, p<.05$ ) at classroom level (see Appendix 1 for the final models $)^{1}$. This mediation was significant $(\mathrm{z}=2.40, p<.05)$. At classroom level, the coefficients of mastery goal structure reduced its value from $\gamma=0.56, p<.001$ to $\gamma=0.27$, n.s., and the value was no longer significant. This means full mediation.

At student level, mastery goal structure was a positive predictor of peer modeling $(\gamma=0.50, p<.001)$. Then promoting interaction predicted peer modeling $(\gamma=0.34, p<.001)$. Student level mediation was significant $(\mathrm{z}=5.42, p<.001)$. The final results of the model are presented in Figure 2 and Table A2.

\section{Discussion}

The purpose of this study was to examine the effects of classroom goal structures on students' motivation and achievement related behaviors and tested the mediation effects of teachers promoting interaction. Our hypothesis was that mastery goal structures influenced intrinsic motivation and peer modeling

\footnotetext{
${ }^{1}$ Performance goal structure also reached significance $(\gamma=0.22, p<.01$ for classroom level, $\gamma=0.20, p<.001$ for student level). However, performance goal structure did not predict promoting interaction at both levels, so we omitted performance goal structure from the final model.
}

through teachers promoting interaction. It is noteworthy that we partitioned between classroom-level variances and student-level variances and examined the mediation processes. Mastery goal structures and teachers promoting interaction were classroom variables by nature. The characteristics of the classroom environment and teachers' educational practice should be shared by students in the same classroom. However, each student can perceive the characteristic differently. Thus, it is necessary to treat the group-level variables (i.e., goal structures and teachers promoting interaction) after dividing the variance to classroom-level variance and student-level variance. Hereafter, we would discuss the mediation process considering this partitioning.

At the classroom level, the hypothesized mediation process for intrinsic motivation was confirmed. That is, mastery goal structure was related to students' intrinsic motivation, and the relationships were partly mediated by teachers promoting interaction. This implies that teachers frequently encourage students to interact with their peers in the classrooms that have the characteristics of mastery goal structures, and the interaction increases the average level of intrinsic motivation for mathematical learning. The advantages of classrooms with mastery goal structures are mediated by teachers promoting interaction among students. In contrast, the mediation process was not fully confirmed at the student level. Although the perception of mastery goal structure was associated with the perception of teachers promoting interaction, it did not predict intrinsic motivation significantly. Mastery goal structure was directly related to intrinsic motivation. The student level results are consistent with considerable research on the positive effects of mastery goal structures (Meece et al., 2006; Midgley et al., 1995; Murayama \& Elliot, 2009; Roeser et al., 1996; Urdan \& Midgley, 2003; Urdan \& Schoenfelder, 2006; Wolters, 2004). In sum, in classrooms that emphasize mastering new skills, the average level intrinsic motivation is high. However, the effects of the characteristics of mastery goal structures shared by students in a classroom are mediated by classroom-level variables such as teachers' instructional strategies (i.e., promoting interaction).

The hypothesized mediation process at the classroom level was also confirmed for peer modeling. Mastery goal structure related to students' peer modeling and the relationship was mediated by teachers promoting interaction. The more classrooms are mastery oriented, the more students in the classrooms tend to model peers' learning behaviors with their teachers' encouragement. At the student level, the mediation process was also confirmed. Students who perceive more mastery goal structure than the average of their classmates tend to perceive the emphasis of promoting interaction and, then, report higher level of peer modeling. Peer modeling has been mainly examined in experimental studies (Schunk, 1998). In contrast, this study suggested that students use peer modeling as a kind of learning strategy, and the use is influenced by the characteristics of classrooms.

Performance goal structures did not predict teachers promoting interaction or intrinsic motivation at either the classroom or student levels, although they did predict peer modeling. The mediation processes of performance goal structures were not totally confirmed. Some previous studies reported negative effects of performance goal structures (Kaplan et al., 2002; Roeser et al., 1996; Ryan et al., 1998), and others reported no negative effects (Midgley et al., 1995; Ryan \& Patrick, 2001). Negative effects of performance goal structures were not found 


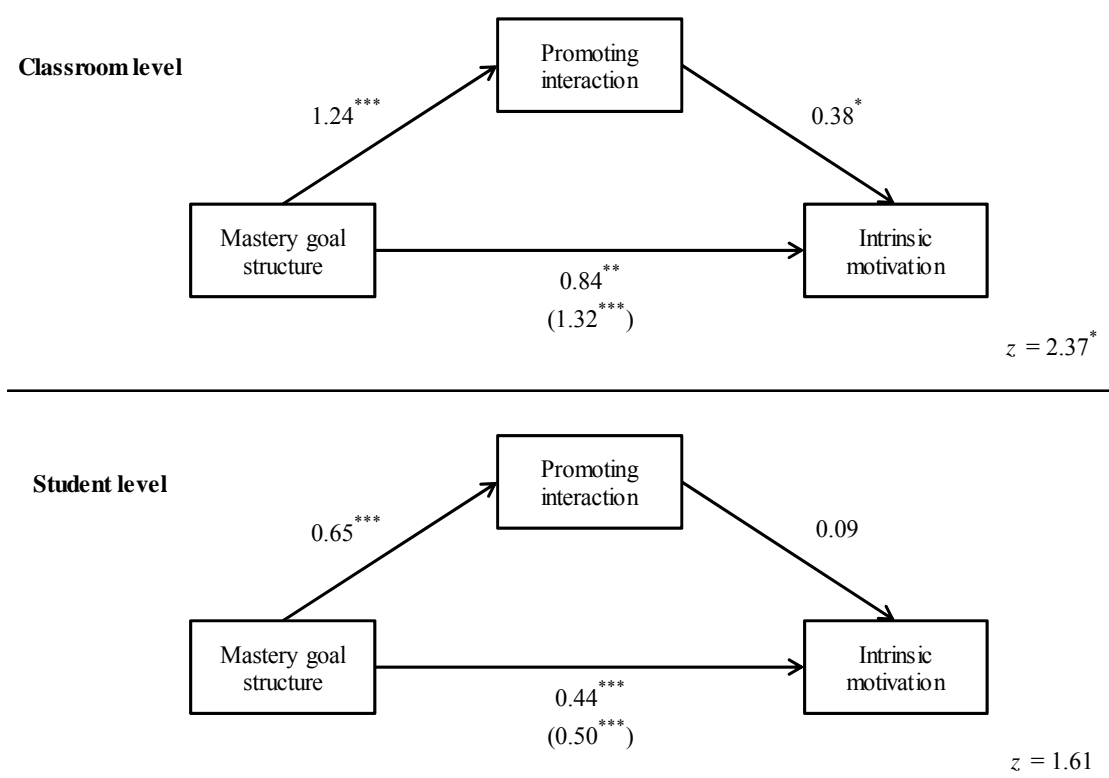

Figure 1.

Multilevel mediation model predicting intrinsic motivation. Regression coefficients in parentheses represent direct effects before adding promoting interaction. ${ }^{*} p<.05,{ }^{* *} p<.01,{ }^{* * *} p<.001$.

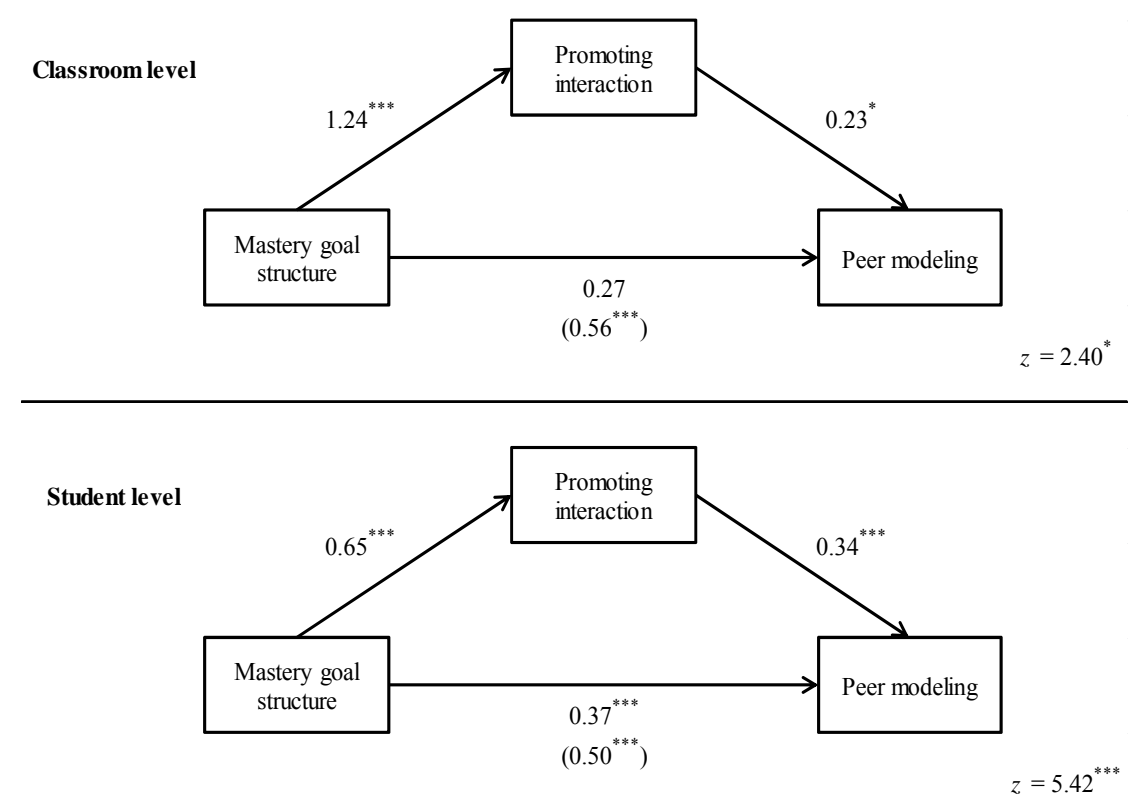

Figure 2.

Multilevel mediation model predicting peer modeling. Regression coefficients in parentheses represent direct effects before adding promoting interaction. ${ }^{*} p<.05,{ }^{* * *} p<.001$.

in this study.

This study revealed that teachers promoting interaction mediated the effects of classroom mastery goal structures on intrinsic motivation and peer modeling. These results are consistent with previous studies (Patrick, 2004; Patrick et al., 2011). It can be understood that the positive effects of promoting interaction among students for the following two reasons. First, interaction with peers can give students resources that support their learning. The more time students spend with peers in their learning, the more easily they can ask classmates for help when confronting academic difficulties. Students can also acquire skills by observing peers. This is reflected in the relationship between promoting interaction and peer modeling in this study. Second, students can receive emotional support by interacting with peers. Some researchers suggest that positive relationships with friends and peers in the classroom play an important role in students' academic motivation (Anderman \& Freeman, 2004; Wentzel, 2005). Promoting peer interaction is an important teaching strategy that influences students' learning and motivation.

The main contribution of this study is to reveal classroom motivational processes in terms of teachers promoting interac- 
tion among students. Previous studies mainly focused on students' personal goals as a mediator of classroom effects (e.g., Anderman \& Anderman, 1999; Roser et al., 1996; Midgley et al., 1995). Given that a classroom environment is shared by students, we should pay attention to classroom variables. In this study, the mediation process for intrinsic motivation was confirmed at the classroom level. Among classroom variables, teachers' instructional practices can have a significant impact on students' learning. Because a classroom is a social place by nature, instructional strategies that support peer relationships and student interaction are especially important. Therefore, it is necessary for educators and researchers to examine the role of teaching strategies of promoting peer interaction.

This study provides some prospections for future motivational research. In this study, teachers' promoting interaction mediated the effects of classroom characteristics (i.e., mastery goal structures) on the students' intrinsic motivation and peer modeling. This findings show that interaction between teachers and students are critical for students' achievements related behavior and motivation. Thus, future research can gain important insights regarding achievement processes by focusing on interaction between teachers and students with more details. In addition, this study revealed few differences between classroom level and student level. It may be profitable to pay attention to student-student interaction as well as teacher-student interaction.

\section{Limitations}

This research has some limitations. First, all data were collected at one point in time. The model examined in this study assumed a causal order in which mastery goal structures influence teachers promoting interaction, which in turn affects intrinsic motivation and peer modeling. The simultaneous measurement, however, makes it difficult to interpret the findings as a causal sequence. To examine the motivational processes in terms of causal sequence in more detail, a longitudinal study would add valuable information. Second, classroom variables were measured in terms of students' ratings. We measured students' perceptions of classroom goal structures and teachers promoting interaction and partitioned the variance into two levels (classroom and individual student levels). In addition, we could measure the variables through teachers' reports and classroom observation. Some researchers have examined the effects of classroom combining students' and teachers' self-reported data with the observational data (Turner et al., 2002; Turner et al., 2003). Patrick (2004) found that teachers in the classroom which was rated as high mastery oriented by the students emphasized understanding and self-referenced improvement through classroom observations. It may be that observed data and students' reported data of classroom goal structures and teachers promoting interaction have different effects on students' motivation. Thus, multiple measurements including students' or teachers' self-report and classroom observation would be useful to consider the effects of classroom variables.

\section{REFERENCES}

Ames, C. (1992). Classroom: Goals, structures, and student motivation. Journal of Educational Psychology, 84, 261-271. doi:10.1037/0022-0663.84.3.261

Ames, C., \& Ames, R. (1984). Systems of student and teacher motivation: Toward a qualitative definition. Journal of Educational Psy- chology, 76, 535-556. doi:10.1037/0022-0663.76.4.535

Ames, C., \& Archer, J. (1988). Achievement goals in the classroom: Students' learning strategies and motivation processes. Journal of Educational Psychology, 80, 260-267.

doi:10.1037/0022-0663.80.3.260

Anderman, L. H., \& Anderman, E. M. (1999). Social predictors of changes in students' achievement goal orientation. Contemporary Educational Psychology, 25, 21-37. doi:10.1006/ceps.1998.0978

Anderman, L. H., \& Freeman, T. M. (2004).Students' sense of belonging in school. In P. R. Pintrich, \& M. L. Maehr (Eds.), Advances in motivation and achievement: Vol. 13. motivating students, improving schools: The legacy of carol midgley (pp. 27-63). Greenwich, CT: JAI Press.

Bliese, P. D. (2000). Within-group agreement, non-independence, and reliability: Implications for data aggregation and analysis. In K. J. Klein, \& S. W. Kozlowski (Eds.), Multilevel theory, research, and methods in organizations (pp. 349-381). San Francisco: Jossey-Bass.

Brophy, J. (2004). Motivating students to learn (2nd ed.). Hillsdale, NJ: Lawrence Erlbaum Associates.

Dweck, C. S., \& Leggett, E. L. (1988). A social-cognitive approach to motivation and personality. Psychological Review, 95, 256-273. doi:10.1037/0033-295X.95.2.256

Elliot, A. J. (2005). A conceptual history of the achievement goal construct. In A. J. Elliot, \& C. S. Dweck (Eds.), Handbook of competence and motivation (pp. 52-72). New York: Guilford Press.

Elliot, A. J., \& Church, M. A. (1997). A hierarchical model of approach and avoidance achievement motivation. Journal of Personality and Social Psychology, 72, 218-232. doi:10.1037/0022-3514.72.1.218

Elliot, A. J., \& McGregor, H. A. (2001). A $2 \times 2$ achievement goal framework. Journal of Personality and Social Psychology, 80, 501519. doi:10.1037/0022-3514.80.3.501

Harackiewicz, J. M., Barron, K. E., Pintrich, P. R., Elliot, A. J., \& Thrash, T. M. (2002). Revision of achievement goal theory: Necessary and illuminating. Journal of Educational Psychology, 94, 638645. doi: $10.1037 / 0022-0663.94 .3 .638$

Hyde, J. S., \& Durik, A. (2005). Gender, competence and motivation. In A. J. Elliot, \& C. S. Dweck (Eds.), Handbook of competence and motivation (pp. 375-392). New York: Guilford Press.

Kaplan, A., Gheen, M., \& Midgley, C. (2002). Classroom goal structure and student disruptive behaviour. British Journal of Educational Psychology, 72, 191-211. doi:10.1348/000709902158847

Kaplan, A., Middleton, M. J., Urdan, T., \& Midgley, C. (2002). Achievement goals and goal structures. In C. Midgley (Ed.), Goals, goal structures, and patterns of adaptive learning (pp. 21-53). Mahwah, NJ: Erlbaum.

Lepper, M. R., Corpus, J. H., \& Iyengar, S. S. (2005). Intrinsic and extrinsic motivational orientation in the classroom: Age differences and academic correlates. Journal of Educational Psychology, 97, 184196. doi:10.1037/0022-0663.97.2.184

Maehr, M. L., \& Zusho, A. (2009). Achievement goal theory: The past, present, and future. In K. R. Wentzel, \& A. Wigfield (Eds.), Handbook of motivation at school (pp. 77-104). New York: Routledge.

Meece, J. L., Anderman, E. M., \& Anderman, L. H. (2006). Classroom goal structure, student motivation, and academic achievement. Annual Review of Psychology, 57, 487-503. doi:10.1146/annurev.psych.56.091103.070258

Meece, J. L., Blumenfeld, P. C., \& Hoyle, R. H. (1988). Students' goal orientations and cognitive engagement in classroom activities. Journal of Educational Psychology, 80, 514-523. doi:10.1037/0022-0663.80.4.514

Midgley, C. Maehr, M. L., Hruda, L. A., Anderman, E., Anderman, L., Gheen, M., Kaplan, A., Kumar, R., Middleton, M. J., Nelson, J., \& Urdan, T. (2000). Manual for the Patterns of Adaptive Learning Scale. Ann Arbor, MI: University of Michigan.

Midgley, C., Anderman, E., \& Hicks, L. (1995). Differences between elementary and middle school teachers and students: A goal theory approach. Journal of Early Adolescence, 15, 90-113. doi:10.1177/0272431695015001006

Miki, K., \& Yamauchi, H. (2005). Perceptions of classroom goal structures, personal achievement goal orientations, and learning strategies. Japanese Journal of Psychology, 76, 260-268. 
doi: $10.4992 /$ jjpsy. 76.260

Murayama, K., \& Elliot, A. J. (2009).The joint influence of personal achievement goals and classroom goal structures on achievementrelevant outcomes. Journal of Educational Psychology, 101, 432447. doi:10.1037/a0014221

Nicholls, J. G. (1984). Achievement motivation: Conception of ability, subjective experience, task choice, and performance. Psychological Review, 91, 328-346. doi:10.1037/0033-295X.91.3.328

Okada, R., Nakaya, M., Ito, T., \& Ohtani, K. (2010). Individual differences in peer-modeling. Poster Presented at the Japanese Association of Educational Psychology 52nd Annual Conference, Japan.

Patrick, H. (2004). Re-examining classroom mastery goal structure. In P. R. Pintrich, \& M. L. Maehr (Eds.), Advances in motivation and achievement: Vol. 13. Motivating students, improving schools: The legacy of carol midgley (pp. 233-263). Greenwich, CT: JAI Press.

Patrick, H., Anderman, L. H., Ryan, A. M., Edelin, K., \& Midgley, C. (2001). Teachers' communication of goal orientations in four fifthgrade classrooms. The Elementary School Journal, 102, 35-58. doi: $10.1086 / 499692$

Patrick, H., Kaplan, A., \& Ryan, A. M. (2011). Positive classroom motivational environments: Convergence between mastery goal structure and classroom social climate. Journal of Educational Psychology, 103, 367-382. doi:10.1037/a0023311

Patrick, H., Ryan, A. M., \& Kaplan, A. (2007). Early adolescents' perceptions of the classroom social environment, motivational beliefs, and engagement. Journal of Educational Psychology, 99, 83-98. doi:10.1037/0022-0663.99.1.83

Pintrich, P. R., \& De Groot, E. V. (1990). Motivational and self-regulated learning components of classroom academic performance. Journal of Educational Psychology, 82, 33-40.

doi:10.1037/0022-0663.82.1.33

Roeser, R. W., Midgley, C., \& Urdan, T. C. (1996). Perceptions of the school psychological environment and early adolescents' psychological and behavioral functioning in school: The mediating role of goals and belonging. Journal of Educational Psychology, 88, 408432. doi:10.1037/0022-0663.88.3.408

Ryan, A. M. (2000). Peer groups as a context for the socialization of adolescents' motivation, engagement, and achievement in school. Educational Psychologist, 35, 101-111. doi:10.1207/S15326985EP3502_4

Ryan, A. M., \& Patrick, H. (2001). The classroom social environment and changes in adolescents' motivation and engagement during middle school. American Educational Research Journal, 38, 437-460. doi: $10.3102 / 00028312038002437$

Ryan, A. M., Gheen, M. H., \& Midgley, C. (1998). Why do some students avoid asking for help? An examination of the interplay among students' academic efficacy, teachers' social-emotional role, and the classroom goal structure. Journal of Educational Psychology, 90, 528-535. doi: $10.1037 / 0022-0663.90 .3 .528$

Schunk, D. H. (1998). Teaching elementary students to self-regulate practice of mathematical skills with modeling. In D. H. Schunk, \& B.
J. Zimmerman (Eds.), Self-regulated learning, from teaching to selfreflective practice (pp. 137-159). New York: Guilford Press.

Schunk, D. H., \& Hanson, A. R. (1985). Peer models: Influence on children's self-efficacy and achievement. Journal of Educational Psychology, 77, 313-322. doi:10.1037/0022-0663.77.3.313

Schunk, D. H., \& Hanson, A. R. (1989). Self-modeling and children's cognitive skill learning. Journal of Educational Psychology, 81, 155163. doi: $10.1037 / 0022-0663.81 .2 .155$

Tanaka, A., \& Yamauchi, H. (2000). Causal models of achievement motive, goal orientation, intrinsic interest, and academic achievement in classroom. The Japanese Journal of Psychology, 71, 317-324. doi:10.4992/jjpsy.71.317

Turner, J. C., \& Meyer, D. K. (2009). Understanding motivation in mathematics: What is happening in classrooms? In K. R. Wentzel, \& A. Wigfield (Eds.), Handbook of motivation at school (pp. 527-552). New York: Routledge.

Turner, J. C., Meyer, D. K., Midgley, C., \& Patrick, H. (2003). Teacher discourse and sixth graders' reported affect and achievement behaveiors in two high-mastery/high-performance mathematics classrooms. The Elementary School Journal, 103, 357-382. doi:10.1086/499731

Turner, J. C., Midgley, C., Meyer, D. K., Gheen, M., Anderman, E. M., $\&$ Kang, Y. (2002). The classroom environment and students' reports of avoidance strategies in mathematics: A multimethod study. Journal of Educational Psychology, 94, 88-106. doi: $10.1037 / 0022-0663.94 .1 .88$

Urdan, T., \& Midgley, C. (2003). Changes in the perceived classroom goal structure and pattern of adaptive learning during early adolescence. Contemporary Educational Psychology, 28, 524-551. doi:10.1016/S0361-476X(02)00060-7

Urdan, T., \& Schoenfelder, E. (2006). Classroom effects on student motivation: Goal structures, social relationships, and competence beliefs. Journal of School Psychology, 44, 331-349. doi:10.1016/j.jsp.2006.04.003

Wentzel, K. R. (2005). Peer relationships, motivation, and academic performance at school. In A. J. Elliot, \& C. S. Dweck (Eds.), Handbook of competence and motivation (pp. 279-296). New York: Guilford Press.

Wolters, C. A. (2004). Advancing achievement goal theory: Using goal structures and goal orientations to predict students' motivation, cognition, and achievement. Journal of Educational Psychology, 96, 236-250. doi:10.1037/0022-0663.96.2.236

Yamauchi, H., \& Tanaka, K. (1998). Relations of autonomy, self-referenced beliefs, and self-regulated learning among Japanese children. Psychological Reports, 82, 803-816. doi:10.2466/pr0.1998.82.3.803

Young, M. R. (2005). The motivational effects of the classroom environment in facilitating self-regulated learning. Journal of Marketing Education, 27, 25-40. doi:10.1177/0273475304273346

Zhang, Z., Zyphur, M. J., \& Preacher, K. J. (2009). Testing multilevel mediation using hierarchical linear models. Organizational Research Methods, 12, 695-719. doi:10.1177/1094428108327450 


\section{K. OHTANI ET AL.}

\section{Appendix 1}

Final models of the multilevel meditational models.

\section{Intrinsic Motivation}

Step 1

Intrinsic motivation $=\beta_{0 j}+\beta_{1 j}$ (gender) $+\beta_{2 j}$ (mastery goal structure) $+r_{i j}$

$\beta_{0 j}=\gamma_{00}+\gamma_{01}$ (school grade $)+\gamma_{02}($ mastery goal structure $)+$ $u_{0 j}, \beta_{1 j}=\gamma_{10}, \beta_{2 j}=\gamma_{20}$

Step 2

Promoting interaction $=\beta_{0 j}+\beta_{1 j}$ (gender) $+\beta_{2 j}$ (mastery goal structure $)+r_{i j}$

$\beta_{0 j}=\gamma_{00}+\gamma_{01}$ (school grade) $+\gamma_{02}$ (mastery goal structure) + $u_{0 j}, \beta_{1 j}=\gamma_{10}, \beta_{2 j}=\gamma_{20}$

Step 3

Intrinsic motivation $=\beta_{0 j}+\beta_{1 j}$ (gender) $+\beta_{2 j}$ (mastery goal structure $)+\beta_{3 j}$ (promoting interaction) $+r_{i j}$

$\beta_{0 j}=\gamma_{00}+\gamma_{01}($ school grade $)+\gamma_{02}$ (mastery goal structure $)+$ $\gamma_{03}$ (promoting interaction) $+u_{0 j}, \beta_{1 j}=\gamma_{10}, \beta_{2 j}=\gamma_{20}, \beta_{3 j}=\gamma_{30}$

\section{Peer Modeling}

Step 1

Peer modeling $=\beta_{0 j}+\beta_{1 j}$ (gender) $+\beta_{2 j}$ (mastery goal structure) $+r_{i j}$

$\beta_{0 j}=\gamma_{00}+\gamma_{01}$ (school grade $)+\gamma_{02}$ (mastery goal structure $)+$ $u_{0 j}, \beta_{1 j}=\gamma_{10}, \beta_{2 j}=\gamma_{20}$

Step 2

Promoting interaction $=\beta_{0 j}+\beta_{1 j}$ (gender) $+\beta_{2 j}$ (mastery goal structure) $+r_{i j}$

$\beta_{0 j}=\gamma_{00}+\gamma_{01}$ (school grade $)+\gamma_{02}$ (mastery goal structure $)+$ $u_{0 j}, \beta_{1 j}=\gamma_{10}, \beta_{2 j}=\gamma_{20}$

Step 3

Peer modeling $=\beta_{0 j}+\beta_{1 j}$ (gender) $+\beta_{2 j}$ (mastery goal structure) $+\beta_{3 j}$ (promoting interaction) $+r_{i j}$

$\beta_{0 j}=\gamma_{00}+\gamma_{01}$ (school grade) $+\gamma_{02}$ (mastery goal structure) + $\gamma_{03}$ (promoting interaction) $+u_{0 j}, \beta_{1 j}=\gamma_{10}, \beta_{2 j}=\gamma_{20}, \beta_{3 j}=\gamma_{30}$

\section{Appendix 2}

Table A1.

The result of multilevel mediation model predicting intrinsic motivation.

\begin{tabular}{|c|c|c|c|c|c|c|}
\hline \multirow{3}{*}{ Classroom level } & \multicolumn{2}{|c|}{ Step 1} & \multicolumn{2}{|c|}{ Step 2} & \multicolumn{2}{|c|}{ Step 3} \\
\hline & \multicolumn{2}{|c|}{ To intrinsic motivation } & \multicolumn{2}{|c|}{ To promoting interaction } & \multicolumn{2}{|c|}{ To intrinsic motivation } \\
\hline & Coefficient & $S E$ & Coefficient & SE & Coefficient & $S E$ \\
\hline Intercept $\left(\gamma_{00}\right)$ & $2.85^{* * *}$ & 0.14 & $3.87^{* * *}$ & 0.14 & $2.92^{* * *}$ & 0.13 \\
\hline Grade $\left(\gamma_{01}\right)$ & $0.13^{*}$ & 0.06 & 0.10 & 0.06 & 0.09 & 0.06 \\
\hline Mastery goal structure $\left(\gamma_{02}\right)$ & $1.32^{* * *}$ & 0.20 & $1.24^{* * *}$ & 0.20 & $0.84^{* *}$ & 0.04 \\
\hline Promoting interaction $\left(\gamma_{03}\right)$ & - & & - & & $0.38^{*}$ & 0.15 \\
\hline \multicolumn{7}{|l|}{ Random effects of intercept $\left(u_{0}\right)$} \\
\hline Variance & $0.041^{* * *}$ & & $0.067^{* * *}$ & & $0.029^{*}$ & \\
\hline The amount of variance explained in each step & \multicolumn{2}{|c|}{$67.98 \%$} & \multicolumn{2}{|c|}{$52.46 \%$} & \multicolumn{2}{|c|}{$9.17 \%$} \\
\hline \multicolumn{7}{|l|}{ Student level } \\
\hline Gender $\left(\gamma_{10}\right)$ & $0.47^{* * *}$ & 0.09 & -0.05 & 0.04 & $0.48^{* * *}$ & 0.09 \\
\hline Mastery goal structure $\left(\gamma_{20}\right)$ & $0.50^{* * *}$ & 0.06 & $0.65^{* * *}$ & 0.03 & $0.44^{* * *}$ & 0.06 \\
\hline Promoting interaction $\left(\gamma_{30}\right)$ & - & & - & & 0.10 & 0.06 \\
\hline The amount of variance explained in each step & \multicolumn{2}{|c|}{$7.73 \%$} & \multicolumn{2}{|c|}{$34.49 \%$} & \multicolumn{2}{|c|}{$0.01 \%$} \\
\hline
\end{tabular}

${ }^{*} p<.05,{ }^{* *} p<.01,{ }^{* * *} p<.001$

Table A2.

The result of multilevel mediation model predicting peer modeling.

\begin{tabular}{|c|c|c|c|c|c|c|}
\hline \multirow[b]{3}{*}{ Classroom level } & \multicolumn{2}{|c|}{ Step 1} & \multicolumn{2}{|c|}{ Step 2} & \multicolumn{2}{|c|}{ Step 3} \\
\hline & \multicolumn{2}{|c|}{ To peer modeling } & \multicolumn{2}{|c|}{ To promoting interaction } & \multicolumn{2}{|c|}{ To peer modeling } \\
\hline & Coefficient & SE & Coefficient & SE & Coefficient & SE \\
\hline Intercept $\left(\gamma_{00}\right)$ & $3.87^{* * *}$ & 0.09 & $3.87^{* * *}$ & 0.14 & $3.90^{* * *}$ & 0.08 \\
\hline Grade $\left(\gamma_{01}\right)$ & $0.09^{*}$ & 0.09 & 0.10 & 0.06 & 0.06 & 0.04 \\
\hline Mastery goal structure $\left(\gamma_{02}\right)$ & $0.56^{* * *}$ & 0.11 & $1.24^{* * *}$ & 0.20 & 0.27 & 0.17 \\
\hline Promoting interaction $\left(\gamma_{03}\right)$ & - & & - & & $0.23^{*}$ & 0.09 \\
\hline Variance & $0.010^{\dagger}$ & & $0.067^{* * *}$ & & $0.007^{\dagger}$ & \\
\hline The amount of variance explained in each step & \multicolumn{2}{|c|}{$46.52 \%$} & \multicolumn{2}{|c|}{$52.46 \%$} & \multicolumn{2}{|c|}{$14.21 \%$} \\
\hline \multicolumn{7}{|l|}{ Student level } \\
\hline Gender $\left(\gamma_{10}\right)$ & $-0.14^{*}$ & 0.06 & -0.05 & 0.04 & $-0.12^{*}$ & 0.05 \\
\hline Mastery goal structure $\left(\gamma_{20}\right)$ & $0.50^{* * *}$ & 0.03 & $0.65^{* * *}$ & 0.03 & $0.37^{* * *}$ & 0.05 \\
\hline Promoting interaction $\left(\gamma_{30}\right)$ & - & & - & & $0.34^{* * *}$ & 0.06 \\
\hline
\end{tabular}

${ }^{\dagger} p<.10,{ }^{*} p<.05,{ }^{* *} p<.01,{ }^{* * *} p<.001$. 